\title{
HUBUNGAN ANTARA MUTU PELAYANAN DENGAN KESETIAAN PASIEN ( SURVEY PADA PASIEN BAGIAN JANTUNG RUMAH SAKIT INTERNASIONAL BINTARO )
}

\author{
Henry Eryanto*
}

\begin{abstract}
This research was aimed at describing connections between : 1) The Quality of Services to the Patient Loyalty, 2)The Satisfaction to the Patient Loyalty, 3) The Quality of Services and Patients Satisfaction, all together, to the patient loyalty. This study was held in the Bintaro International Hospital, Tangerang. The method of research is survey method. The population consist of all internal disease patients of Bintaro International Hospital, Tangerang. Sample of research are 40 patients which were taken by random sampling method. The result of research, that the service quality and the patient satisfaction themselves or all together, giving significant result toward the patient loyalty. The attitude towards the improvement quality of service, and patient satisfaction need to be trained for the employees of Bintaro International Hospital. This matter cannot be separated from the employees recruitment. Spesifically for the best services for their patients, beside that matters the hospital management must be improved their tools and equipment that they're used, and would be hold the trainings for their employees.
\end{abstract}

Keywords: Quality of Service, Satisfaction, Loyalty.

\section{PENDAHULUAN}

Kualitas sumber daya manusia yang kita miliki perlu secara terus menerus ditingkatkan agar mampu berperan dalam persainganglobal maka sebagai suatu bangsa yang besar. Oleh karena itu peningkatan kualitas sumber daya manusia harus dilakukan secara terencana, terarah, intensif, efektif dan efisien dalam proses pembangunan, kalau kita tidak ingin bangsa ini kalah bersaing dalam menjalani era globalisasi tersebut.

* Henry Eryanto. Dosen Fakultas Ekonomi Universitas Negeri Jakarta.
Berbicara mengenai kualitas sumber daya manusia, kesehatan memegang peran yang sangat penting dalam proses peningkatan kualitas sumber daya manusia. Peningkatan kualitas kesehatan merupakan suatu proses yang terintegrasi dengan proses peningkatan sumber daya manusia itu sendiri. Menyadari pentingnya peningkatan kualitas sumber daya manusia, maka pemerintah bersama kalangan swasta sama-sama berupaya meningkatkan kualitas sumber daya manusia melalui pembangunan kesehatan yang berkualitas antara lain melalui 
pemakaian alat canggih yang berharga mahal, pemberian pelayanan medis yang sesuai dengan standar profesi medis. Dengan demikian untuk memperoleh sumber daya manusia yang berkualitas tinggi maka derajat kesehatan merekapun haruss optimal.

Dalam upaya mencapai derajat kesehatan yang optimal hal ini tidak lepas dari peranan rumah sakit sebagai unsur pelaksana di bidang pelayanan kesehatan. Rumah sakit sebagai ujung tombak yang berhadapan langsung dengan penderita atau pasien yang memerlukan bantuan pelayanan kesehatan harus dapat memberikan pelayanan yang berkualitas.

Sebagaimana telah dijelaskan di atas, bahwa keterlibatan masyarakat dalam memfasilitasi kesehatan sangat menentukan dalam meningkatkan derajat kesehatan masyarakat. Karena kemampuan pemerintah dalam kondisi sekarang ini sangat terbatas dalam menyediakan sarana dan prasarana kesehatan.

Oleh karena itu peran serta masyarakat dalam upaya memberikan pelayanan kesehatan melalui rumah sakit swasta sangat diharapkan, hal ini terlihat dengan dikeluarkanya Peraturan Menteri Kesehatan Republik Indonesia Nomor: 920/Men.Kes/Per /XIII/1986 tentang upaya Pelayanan Kesehatan Swasta di bidang Medik sebagai pengganti Peraturan Menteri Kesehatan Republik Indonesia Nomor: 532/Men.Kes/Per/XI/1982 yang dipandang tidak memadai lagi.

Untuk memperjelas peran masyarakat dalam upaya memberikan pelayanan kesehatan terlihat pada peraturan Menteri Kesehatan Republik Indonesia tersebut bahwa peran serta masyarakat swasta secara merata, terjangkau dan dapat diberikan oleh masyarakat sesuai dengan sistem kesehatan nasional semakin meningkat dan berkembang (Peraturan Menteri kesehatan Republik Indonesia 1986:920).

Dan peraturan Menteri Kesehatan tersebut di atas, tampak bahwa upaya pelayanan kesehatan swasta hendaknya dapat menjangkau seluruh lapisan masyarakat, walaupun dalam pengelolaannya dilaksanakan berdasarkan prinsipprinsip ekonomi dengan memperhatikan azas-azas efisiensi dan efektifitas. Dengan terbukanya peran masyarakat dalam pelayanan kesehatan maka semakin pesat pula pertumbuhan Rumah Sakit Swasta, khususnya di kota-kota besar seperti di wilayah JABOTABEK dan sekitarnya.

Oleh karena itu masyarakat penyelenggara rumah sakit swasta dituntut pula untuk meningkatkan dan mengembangkan sarana dan prasarana, sumber daya manusia, pengelolaan rumah sakit, dan mutu pelayanan agar dapat dihasilkan proses dan pelayanan yang bermutu, efektif dan efisien yang berorientasi pada kepentingan pasien.

Upaya memenuhi tuntutan masyarakat pengguna jasa pelayanan kesehatan telah dilakukan oleh pihak rumah sakit sebagai pemberi jasa kesehatan dengan menawarkan berbagai paket dan program pelayanan kesehatan, selain menyediakan sarana dan prasarana yang canggih serta berkualitas baik. 
Berdasarkan kenyataan ini, pihak rumah sakit swasta yang ingin berkembang atau paling tidak bertahan hidup harus dapat memberikan kepada para pasien berupa jasa pelayanan yang bermutu lebih baik, harga lebih murah dari pada para pesaingnya. Apabila pasien merasa tidak puss atas mutu pelayanan yang diberikan oleh pihak rumah sakit tersebut maka mereka akan pindah kerumah sakit lain yang dapat memberikan pelayanan lebih bermutu dan kepuasan yang jauh lebih baik.

Karena itu agar suatu rumah sakit bisa bertahan sekaligus memenangkan persaingan tersebut, maka mereka harus memiliki pasien yang setia (customer loyalty). Memiliki pasien yang setia merupakan dambaan dari setiap rumah sakit, keinginan seperti ini sebenamya tidak hanya dambaan rumah sakit saja melainkan keinginan semua perusahaan. Balk perusahaan barang maupun perusahaan jasa keduanya berusaha mendapatkan pelanggan yang setia apalagi di era tingkat persaingan yang bukan saja sekedar kompetitif namun sudah hiper kompetitif, pelanggan yang setia menjadi sumber kehidupan bagi perusahaan sehingga dapat terus berkembang hidup.

Karenanya, menciptakan kesetiaan para pasien rumah sakit menjadi inti kegiatan bagi setiap rumah sakit. Tetapi untuk mewujudkan hal ini tidaklah semudah yang diduga. Sekarang ini banyak pasien yang semakin kritis terhadap mutu .pelayanan kesehatan yang mereka terima. Hal ini terlihat dengan banyaknya tulisan pembaca di koran atau majalah yang membahas tentang pelayanan suatu rumah sakit. Keluhan ini umumnya tentang pelayanan awal, sikap perawat dan dokter dalam menangani pasien, sarana yang tersedia, kelengkapan obat-obatan, kebersihan dan pada akhirnya pasien akan pindah ke rumah sakit lain yang memberikan pelayanan yang lebih baik.

Oleh sebab itu berbagai kegiatan dan program yang diselenggarakan oleh rumah sakit yang berusaha untuk mendapatkan pasien yang setia, bukanlah suatu upaya yang sia-sia. Bagi pihak rumah sakit ada beberapa keuntungan yang didapat dengan memiliki pesien yang setia, salah satunya adalah berkurangnya biaya operasional. Karena sebenarnya untuk mendapatkan pasien baru, pihak rumah sakit hares mengeluarkan biaya seperti biaya bauran promosi dan biaya lainnya. Sedangkan untuk mempertahankan pasien yang setia tentunya tidak sebesar biaya untuk menarik pasien baru.

Untuk itulah maka rumah sakit harus melakukan reformasi program demi mendapatkan pasien yang setia. Berbagai cara yang dilakukan oleh pihak rumah sakit dalam rangka membuat pasien setia umpamanya dengan program khusus seperti persalinan, medical check up, dengan harga yang lebih murah. Menyediakan ruang dan tempat tidur, ruangan operasi, ruangan bersalin dan laboratorium yang semuanya berstandar internasional. Selain itu juga mereka menyediakan tenaga 
dokter umum dan dokter spesialis serta tenaga paramedis yang berpengalaman. Selanjutnya rumah sakit swasta dilengkapi pula dengan instalasi farmasi, radiologi, laboratorium dan unit gawat darurat 24 jam. Tetapi selain upaya-upaya tersebut di atas yang terpenting pihak penyelenggara rumah sakit dari semua tingkatan kelas harus menerapkan sistem pelayanan sesuai dengan standar mutu pelayanan yang ditetapkan oleh Direktorat Jendral Pelayanan Medik Departemen Kesehatan Republik Indonesia. Pelayanan medis harus disediakan dan diberikan kepada pasien sesuai dengan ilmu pengetahaun kedokteran mutakhir, serta memanfaatkan kemampuan dan fasilitas rumah sakit secara optimal setia jenis pelayanan medis harus sesuai dengan masing-masing standar pelayanan medis profesi. Tujuan pelayanan medis ialah mengupayakan kesembuhan pasien secara optimal melalui prosedur dan tindakan yang dapat dipertanggung jawabkan (Mulyadi, 1996:8).

Dengan demikian bagi setiap rumah sakit hendaknya memiliki komitmen yang tinggi dalam memberikan pelayanan kesehatan kepada para pasien tanpa memandang tingkat sosial ekonominya, agamanya, sukunya. Karena sebagai pasien mereka adalah konsumen yang hams mendapatkan pelayanan yang sama.

Untuk itu setiap rumah sakit hendaknya selalu memperhatikan program menjaga mutu yang sasarannya adalah pelayanan kesehatan. Dengan pelayanan yang bermutu dalam arti dapat memuaskan setiap pemakai jasa pelayanan kesehatan. Perlu diketahui bahwa pelayanan kesehatan dikatakan bermutu jika menerapkan kode etik dan standar pelayanan serta menerapkan seluruh pelayanan kesehatan yang dapat memuaskan pasien sebagai konsumen sebuah rumah sakit.

Tak lupa pula yang perlu diperhatikan oleh pihak rumah sakit adalah pelayanan dari sumber daya manusia yakni tenaga medis, tenaga para medis dan seluruh personil lainnya di rumah sakit seperti: satpam, juru parkir dan lain-lain.

\section{KAJIAN TEORI Kesetiaan Pasien}

Dalam Kamus Umum Bahasa Indonesia yang dimaksud dengan pasien adalah "orang yang sakit yang dirawat di rumah sakit atau dokter" . Kesetiaan seorang pasien rumah sakit umumnya tidak terlepas dari nama rumah sakit .

David A. Aaker datam bukunya Managing Brand Equity, mengungkapkan bahwa sebuah produk (baik barang maupun jasa) untuk bertahan di pasar yang kompetitif, tidak bisa dilepaskan tanpa merek (brand). Karenanya, bagi sebuah produk memiliki ekuitas merek (brand equity) menjadi tolak ukur yang harus diperhatikan oleh setiap rumah sakit. Tingkat tertinggi dari ekuitas merek, adalah kesetiaan terhadap merek (brand loyalty). Dalam hal ini, kita dapat mengartikan kesetiaan pasien sebenarnya adalah kesetiaan pasien tesebut terhadap 
merek ataunama pada suatu rumah sakit.

Selanjutnya, dalam Customer Bonding: Pathway to Lasting Costumer Loyalty (Richard Cross dan Janet Smith; 1995:9) mengartikan loyalitas pasien dengan kata mengikat pasien yang didefinisikan proses membangun hubungan dengan pasien, agar mampu bertahan dalam pasar yang dewasa ini terfragmentasi dan kelewat terkomersialisasi.

Dalam Customer Bonding, diberikan 5 tahapan proses untuk menjadikan pasien setia terhadap jasa bank. Tahapan-tahapan ini sekaligus merupakan mengukur berapa besar tingkat loyalitas pasien. Dimensi tersebut adalah: 1) Dimensi ikatan berdasarkan kesadaran (awareness) merupakan tingkat pertama dan fundamental. Dimensi ini berperan pada share of mind, ditandai dengan sadarnya pasien akan merek, produk ataujasa sebuah rumah sakit; 2) Dimensi mengasosiasikan identitas (identity) terbentuk bila pasien mengagumi dan mengidentifikasi dengan nilai, sikap atau preferensi gaya hidup yang mereka asosiasikan dengan merek atau produk.

Dimensi selanjutnya yaitu; 3) Dimensi persahabatan (relationship), yang dibangun berdasarkan pertukaran antara rumah sakit dengan pasien. Artinya, terjadi dialog antara pasien dengan rumah sakit.rumah sakit lewat periklanan memberikan satu atau lebih manfaat tak terlihat (informasi, pengakuan) dan manfaat terlihat (poin, produk ekstra dan kredit) maka pasien memberikan informasi mengenai minat mereka. Hal ini ditandai dengan partisipasi pasien memberikan saran pada kotak saran, ataupn teguran-teguran langsung; 4) Dimensi komunitas (community), diartikan sebagai terikatnya pasien dengan (1) merek dan (2) orang lain yang saling berminat dan melakukannya melalui rumah sakit. Bentuk jelasnya adalah pasien merasa bangga dan suka apabila bergabung dengan pasien lain, misalnya dalam bentuk keanggotaan (members club); 5) Dimensi rekomendasi (advocacy), dengan kata lain sebagai pemberian rekomendasi kepada orang lain untuk menggunakan produk yang sama (buyerget-buyer), para wiraniaga menamakannya refferal selling, dan para insan periklanan menyebutnya sebagai iklan dari mulut ke mulut.

\section{Mutu Pelayanan Kesehatan}

Situasi saat ini penuh dengan ketidakpastian dimana seringkali terjadi perubahan yang tidak diduga sebelumnya. Karena itu keterampilan manajemen untuk mengelola ketidakpastian dan kemampuan membuat prediksi merupakan hal yang hams dimiliki apabila perusahaan masih ingin tetap dalam percaturan bisnis. Tidak ada jaminan bahwa suatu bisnis akan bertahan selamanya dan tidak mengalami goncangan badai, hal ini dapat pula terjadi di bidang bisnis jasa kesehatan atau rumah sakit.

Oleh karena itu bila pelaku bisnis memiliki sikap dan prilaku yang memandang remeh dan tidak peduli terhadap mutu, bahkan lebih parah lagi memiliki persepsi bahwa mutu merupakan beban tambahan dan dapat mengganggu kegiatan 
sehari-hari, bila demikian persepsinya maka hal ini akan menimbulkan berbagai kesulitan.

Setiap unit kerja masingmating sibuk sendiri-sendiri, misalnya bagian pemasaran hanya sibuk mengejar target tanpa melihat mutu pelayanannya, bagian keuangan hanya sibuk dengan kegiatan sendiri yaitu mengamati anggaran dan pengeluaran saja. Sehingga semuanya lupa untuk memperhatikan mutu yang merupakan kunci dan keberhasilan.

Padahal apabila mutu mereka tingkatkan akan banyak keuntungan yang dapat mereka terima, misalnya : dapat memangkas pembororsan, mengurangi kesalahan, dan dapat meningkatkan volume penjualan. Selama ini kebanyakan para pengusaha hanya memangkas biaya tanpa memperhatikan mutu. Karena itu suatu jasa diciptakan harus memperhatikan mutu pelayanan yang terbaik bagi pembeli atau customer. Perhatian terhadap mutu harus dimiliki baik pada tingkat pimpinan maupun ditingkat bawahan.

Oleh karena itu mutu pelayanan dibidang kesehatanpun harus ditingkatkan apabila sebuah rumah sakit ingin terus survive. Setiap rumah sakit harus meningkatkan mutu yang lebih baik dari sebelumnya. Karena yang dihadapi adalah para "Customer atau konsumen atau pelanggan atau pasien"1 sebab pada

1 Guna memudahkan pemahaman dalam penulisan ini selanjutnya peneliti menggunakan kata "pasien" sebagai pengganti kata "pelanggan", "konsumen" dan "customer". Juga kata "perusahaan" diganti dengan kata "Rumah Sakit". Karena itu selanjutnya setiap kata yang dikemukakan ahli seperti kata: dasarnya pasien bukan sekedar membeli jasa, melainkan membeli mutu pelayanan yang diberikan, sehingga mereka benar-benar merasa puas. Meraih keuntungan, mengelola bisnis agar terus bertahan dan bergerak maju, tidak terlepas .dari mutu sebagai kunci keberhasilannya.

Jadi hendaknya walaupun mengejar laba sebagai upaya kelangsungan rumah sakit, tidak berarti mengabaikan tingkat mutu pelayanan kepada pasien. Mutu pelayanan kesehatan merupakan suatu persepsi atau pandangan pasien tehadap apa yang mereka terima dibandingkan dengan harapan mereka sebelumnya terhadap mutu pelayanan itu sendiri dengan pandangan Joint Commission on Acreditation of Hospital tentang program menjaga mutu : Program menjaga mutu dapat diartikan sebagai upaya yang dilaksanakan secara berkesinambungan, sistematis, obyektif dan terpadu dalam menetapkan masalah dan penyebab masalah mutu pelayanan berdasarkan standar yang telah ditetapkan, menetapkan dan melaksanakan cara penyelesaian masalah sesuai dengan kemampuan yang tersedia, serta menilai basil yang dicapai dan menyusun saran tindak lanjut untuk lebih meningkatkan mutu pelayanan ( Azrul Azwar; 1994:2).

Apabila dikaitkan dengan mutu pelayanan kesehatan yaitu suatu persepsi atau pandangan pasien

\footnotetext{
"pelanggan", "konsumen", "customer", dan "perusahaan" diganti dengan kata "pasien" dan "Rumah Sakit" . Hal ini disesuaikan dengan objek penelitian.
} 
terhadap pelayanan yang mereka terima dibandingkan dengan harapan mereka sebelumnya terhadap mutu pelayanan itu sendiri. Hal ini sesuai dengan dalam buku Manajemen Kualitas Penerapan Konsep-Konsep Kualitas Dalam Manajemen Bisnis Total , (Vincent Gaspersz; 1997:4) memberikan pendapat mengenai bagaimanapun para manager dari perusahaan yang sedang berkompetisi dalam pasar global harus memberikan perhatian pada defenisi Strategik, yang menyatakan bahwa: kualitas adalah segala sesuatu yang mampu memenuhi keinginan atau kebutuhan pelanggan (Meeting the Needs of Customers).

Dikarenakan sulitnya dalam mengevaluasi kualitas pelayanan maka bagi manajemen industri jasa khususnya rumah sakit harus memiliki komitmen dan tindakan nyata dalam memberikan pelayanan prima kepada para pasien. Pelayanan kesehatan adalah setiap usaha yang diselenggarakan sendiri atau bersamasama dalam suatu organisasi untuk memelihara dan meningkatkan kesehatan perorangan, kelompok, dan atau masyarakat (Azrul Azwar; 1994:1).

Secara umum bahwa yang dimaksud dengan kualitas pelayanan kesehatan adalah yang menunjuk kepada tingkat kesempurnaan pelayanan kesehatan, disatu pihak dapat menimbulkan kepuasan pada setiap pasien sesuai dengan tingkat kepuasan rata-rata, dipihak lain tata cara penyelenggaraannya sesuai dengan kode etik dan standar pelayanan profesi yang telah ditetapkan.

Menurut Azrul Azhar dalam buku Program Pengamatan Pelayanan Kesehatan, ada dua aspek yang menentukan mutu layanan kesehatan, yaitu:

a) Indikator Pelayanan Kesehatan yang bermutu, berdasarkan aspek medis, antara lain:

1. Kesembuhan penyakit yang diderita, makin tinggi angka kesembuhan, makin bermutu pelayanan kesehatan yang diselenggarakan.

2. Efek samping yang dialami, makin rendah efek samping yang timbul, maka makin berutu pelayanan kesehatan.

3. Kematian klien, semakin rendah angka kematian, maka makin bermutu pelayanan kesehatan yang diselenggarakn.

4. Kepuasan klien, makin tinggi tingkat kepuasan klien terhadap pelayanan medis, maka makin tinggi mutu pelayanan

b) Indikator mutu pelayanan berdasarkan aspek non medis, antara lain:

1. Pelayanan kesehatan bermutu apabila penampilan aspek non medis pelayanan kesehatan yang diselenggarakan sesuai dengan kode etik dan standar pelayanan kesehatan yang ditetapkan antara lain:

2. Pengetahuan klien, semakin tinggi tingkat pengetahuan klien akan pelayanan kesehatan yang diselenggarkan, makin tinggi mutu pelayanan kesehatan. 
3. Kemantapan klien, makin tinggi tingkat kemantapan klien,terhadap pelayanan yang diselenggarakan, makin tinggi mutu pelayanan kesehatan.

4. Kepuasan klien, makin tinggi tingkat kepuasan klien terhadap pelayanan non medis, makin tinggi mutu pelayanan kesehatan (Azrul Azwar; 1994:21-23).

Berdasarkan kedua aspek tersebut di atas, maka untuk mencapai suatu mutu pelayanan kesehatan yang baik, maka kedua aspek tersebut di atas harus diperhatikan, sehingga kedua aspek tersebut akan bejalan saling mendukung.

Selain pendapat tersebut di atas, masih banyak literatur yang membahas mengenai mutu pelayanan kesehatan ini, antara lain Donabedian mengatakan bahwa mutu pelayanan kesehatan sifatnya multi dimensi dan bisa dilihat secara umum berdasarkan dua sudut pandang dalam arti luas dan sempit (Donabedian; 1980).

Dalam arti luas, mutu pelayanan tergantung dari beberapa aspek, yaitu seberapa besar interaksi antara tenaga praktisi pelayanan kesehatan dengan pasien, juga berapa banyak keterlibatan pasien untuk berusaha mengembalikan kepercayaan dirinya untuk sembuh, selain itu pengaruh sosial terhadap penigkatan pelayanan serta kenyamanan fasilitas kesehatan yang ada dan yang penting adalah terdapatnya peningkatan kualitas hidup. Sedangkan dalam arti sempit ialah penampilan teknis individual dari praktisi pelayanan kesehatan, baik tenaga medis maupun paramedis.
Selain mutu pelayanan kesehatan dalam arti luas, juga ada yang disebut mutu pelayanan rumah sakit. Menurut Departemen Kesehatan, mutu pelayanan rumah sakit ini adalah derajat kesempurnaan pelayanan rumah sakit untuk memenuhi kebutuhan masyarakat konsumen akan pelayanan kesehatan sesuai dengan standar pelayanan dengan menggunakan potensi sumber daya yang tersedia di rumah sakit secara wajar, -efisien dan efektif serta memberikan rasa aman dan memuaskan sesuai dengan norma, etika, hukum dan sosio dan budaya dengan memperhatikan keterbatasan kemampuan pemerintah dan masyarakat konsumen (Peraturan Menteri Kesehatan Republik Indonesia Nomor 920 atau 1986).

Menurut Donabedian (1980:94) mernyatakan bahwa mutu pelayanan rumah sakit adalah mutu produk akhir dari pelayanan . produk akhir ini merupakan interaksi dan ketergantungan yang rumit antara komponen dan aspek rumah sakit sebagai suatu sistem. Komponen yang mempengaruhi produk akhir ini adalah masukan, proses dan lingkungan. Keluaran dari pelayanan kesehatan yang menunjukan parameter, ada tiga macam, yaitu: 1) Mengacu pada aspek medis: angka kematian dan angka kesembuhan, 2) Mengacu pada aspek pelayanan dan sosial: kepuasan pasien dan opini yang baik dari masyarakat, 3) Mengacu pada sudut pandang ekonomi: efisiensi.

Dari uraian tersebut di atas maka dapat disimpulkan bahwa mutu pelayanan kesehatan yang baik pada 
dasarnya adalah apabila pelayanan tersedia dan terjangkau, aman dan memuaskan bagi pasien yang dilayani.

\section{Hubungan Antara Mutu Pelayanan dengan Kesetiaan Pasien.}

Mutu pelayanan merupakan

faktor penentu keberhasilan dari industri jasa, termasuk juga berlaku bagi sebuah rumah sakit sebagai penyelenggara dari industri jasa kesehatan.

Berdasarkan fakta ini, maka pihak rumah sakit menyadari bahwa untuk dapat bertahan sekaligus memenangkan persaingan dari para pesaing, maka memiliki pasien yang setia sebagai pelanggan merupakan harapan setiap penyelenggara rumah sakit. Harapan ini bukan saja keinginan dari penyelenggara rumah sakit tetapi merupakan harapan dari semua usaha industri baik barang maupun jasa. Keduanya berusaha untuk mendapatkan pelanggan yang setia.

Pelanggan yang setia merupakan urat nadi bagi industri jasa dan barang agar dapat terus berlangsung hidup.

Oleh karena itu, menciptakan kesetiaan pasien sebagai pelanggan merupakan pusat perhatian bagi setiap rumah sakit. Namun untuk mewujudkan hal ini bukanlah suatu pekerjaan yang mudah karena itu pasien sebagai pelanggan rumah sakit merasa dirinya memiliki banyak pilihan apabila tidak mendapatkan pelayanan yang bermutu dari pihak rumah sakit. Kondisi pasien pada masa kini sudah semakin keritis, mereka akan rewel apabila mendapatkan pelayanan yang tidak menyenangkan. Mereka tidak segan-segan lagi menulis di berbagai media masa apabila mendapatkan pelayanan yang tidak memuaskan mereka. Pasien akan pindah ke rumah sakit lain yang menurut mereka dapat memberikan pelayanan yang bermutu.

Berdasarkan uraian di atas maka pihak penyelenggara rumah sakit tidak ada pilihan lain selain berupaya untuk memberikan layanan terbaik kepada pasien.

Seluruh petugas layanan hams benarbenar memiliki kemampuan sesuai dengan bidang tugas mereka di rumah sakit. Petugas rumah sakit hams mewujudkan performance yang baik dalam bertugas, dapat memenuhi jadwal perawatan rutin kepada pasien, memberikan layanan yang cepat, sopan kepada pasien. Para petugas layanan memiliki kemampuan dalam memberikan informasi yang tepat tentang layanan yang diberikan pihak rumah sakit, sehingga pasien dapat memahami informasi dan pada waktunya informasi tersebut dapat membantu mereka.

Selanjutnya bagi tenaga medis diharapkan dapat meningkatkan efektifitas pelayanan kesehatan seperti dapat diatasinya masalah kesehatan secara tepat dan benar, kemudian dapat pula meningkatkan efesiensi pelayanan kesehatan, dalam hal

ini ditujukan mencegah terjadinya pelayanan yang beriebihan ataupun di bawah standar. Selain itu pula mereka diharapkan dapat meningkatkan penerimaan masyarakat terhadap pelayanan kesehatan, hal ini erat kaitannya dengan kesesuaian antara pelayanan kesehatan yang 
diselenggarakan dengan kebutuhan dan tuntutan pemakai jasa pelayanan.

Diharapkan pula mereka mampu melindungi pelaksanaan pelayanan dari kemungkinan timbulnya gugatan hukum dari pasien, dalam hal ini maka mau tidak mau untuk melindungi munculnya gugatan hukum dari pasien yang tidak puas atas pelayanan eksehatan yang mereka terima maka tidak ada pilihan lain yang dilakukan kecuali menyelenggarakan pelayanan kesehatan yang terjamin mutunya.

Berdasarkan bahasan di atas diduga terdapat hubungan positif antara mutu pelayanan dengan kesetiaan pasien. Dengan kata lain makin baik mutu pelayanan, makin tinggi pula kesetiaan pasien.

\section{METODOLOGI PENELITIAN}

Survei dengan pendekatan korelasional. Populasi dalam penelitian ini adalah pasien rawat jalan di bagian penyakit jantung. Sedangkan populasi terjangkaunya adalah pasien rawat jalan pada bagian jantung yang jumlahnya dalam 1 (satu) bulan ratarata 300 orang. Analisis data yang digunakan dalam penelitian ini adalah Regresi sederhana.

\section{HASIL PENELITIAN}

Berdasarkan dari hasil
penelitian ditemukan bahwa
persamaan regresi untuk variabel
kesetiaan pasien atas mutupelayanan
rumah sakit diperoleh regresi $Y=$
$55,64+0,70 X_{1}$. Sehingga dapat
disimpulkan bahwa persamaan regresi
$=55,64+0,70 X_{1}$ signifikan dan linear.

Maka persamaan regresi tersebut adalah perubahan satu unit pada mutu pelayanan(X) akan diikuti oleh 0,70 unit pada kesetiaan pasien $(Y)$ pada arah yang sama dengan konstanta 55,64 .

Koefisien korelasi sederhana kedua variabel adalah korelasi $r_{y 1}=$ $0.75 \quad(a=0,01)$ dan kuadrat dari koefisien korelasi (deerminasi) sebesar $r^{2} y_{1}=0.56$. Ini menunjukkan bahwa $56 \%$ variasi yang terjadi pada kesetiaan pasien dapat dijelaskan oleh mutu pelayanan rumah sakit melalui regresi $Y=55.64+0.70 X_{1}$.

Koefisien korelasi parsial antara mutu pelayanan rumah sakit menurut penilaian pasien $r y_{1 . z}=0.74$. Berdasarkan uji signifikansi tersebut dapat disimpulkan bahwa dengan mengontrol variabel Kepuasan Pasien $\left(X_{2}\right)$ ternyata masih terdapat hubungan positif antara variabel Mutu Pelayanan Rumah Sakit menurut penilaian Pasien dengan Kesetiaan Pasien.

\section{KESIMPULAN}

Berdasarkan dari tujuan penelitian, yaitu ingin mengetahui hubungan antara Mutu Pelayanan dengan Kesetiaan pasien berdasrkan hasil pengolahan dan analisis data, serta pengujian hipotesis, dapat disimpulkan bahwa terdapat hubungan positif antara Mutu Pelayanan dengan kesetiaan Pasien yang dijelaskan oleh koefisien korelasi sebesar 0.75 dan kontribusi Mutu Pelayanan sebesar 0.56 melalui persamaan $Y=55.64+$ $0.70 \mathrm{X}_{1}$. Hal ini berarti meningkat atau menurunnya satu unit Mutu Pelayanan akan diikuti kenaikan atau penurunan 
Kesetiaan Pasien rata-rata sebesar $56 \%$.

\section{DAFTAR PUSTAKA}

Aker David A. 1977. Manajemen

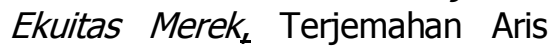
Ananda. Jakarta: Penerbit MitraUtama,

Alma Buchari, 1992. Manajemen Pemasaran \& Pemasaran Jasa, Bandung: Penerbit Alfa Beta.

Azwar Azrul. 1994. Program Menjaga Mutu Pelavanan Kesehatan, Aplikasi Prinsip Lingkaran Pemecahan Masalah. Jakarta: Yayasan Penerbit IDI.

Biran Zainul, 1986. et al. Psikologi Sosial. Jakarta: Penerbit Karunika Universitas Terbuka.

Cross Richard \& Smith Janet. 1995. Customer Bonding:Pathway to Lasting Costumer Loyalty. Lincolnwood, Illinois: NTC Bussiness Book.

Departemen Kesehatan Republik Indonesia, Peraturan Menteri Kesehatan Republik Indonesia Nomor 920/1986, Tentang Pelayanan Kesehatan Rumah Sakit Swasta di Bidang Medik. Jakarta; Depkes.

Donabedian, 1980. Exploration ini Quality Assesment And Monitoring Health Administration, Michigan, Press ann Arbor.

Engel James, Roger D. Blackwell, and Paul F. Miniard, 1990. Customer Behavior, Sixth Edition. Orolondo: The Dryden Press, International Edition.

Gaspersz Vincent. 1997. Manajemen Kualitas Penerapan KonsepKonsep Kualitas Dalam
Manajemen Bisnis Total. Jakarta: Yayasan Indonesia Emas dan Penerbit PT Gramedia Pustaka Utama.

Hardjosoedarmo Soewarno. 1992. Dasar-dasar Total Quality Management. Yogyakarta: Andi.

Indah dan Hartono. 1993. Trend Customer Satisfaction. Segi Majalah Swa, Desember.

Kartajaya Hermawan. 1993. Total Quality Service: Butuh Komitmen Total. Sigi Majalah SWA, Edisi Desember

Kotler Philip. 1995. Manajemen Pemasaran. Terjemahan Ancella Anitawati Hermawan. Jakarta: Penerbit Salemba Empat.

Lou dan D.L. dan A.J.D Bitta, 1993. Consumer Behavior: Concept and Applications, Fourth Edition. Singapore: McGraw-Hill Book Co., Lovelock Cristoper H. 1991. Service Marketing._Englewood Cliffs, Ney Jersey, Prentice Hall,

Mulyadi Bagus, dkk. 1996. Standar Pelayanan Rumah Sakit. Jakarta: Depkes, Ditjen Yanmed, DIT. Rumah Sakit Umum dan Pendidikan,

Peraturan Menteri Kesehatan Republik Indonesia No. 920/Men.Kes /Per/X11/1986, Tentang Upaya Pelayanan Kesehatan Swasta di bidang Medik.

Rukmita Adi Isbandi, 1994. Psikologi Pekerjaan Sosial dan IImu Kesejahteraan Sosial : Dasar-dasar Pemikiran. Jakarta: PT. Raja Grafindo Persada,

Sakaria Mona. 1995. Manajemen Ekspektasi Untuk Meningkatkan Mutu Layanan. Majalah Forum 
Manajemen Prasetya Mulya, Nomor 60,

Soeprapto A.S., 1985. Administrasi Rumali Sakit. Jakarta: CV. Barata Jaya,

Spegell, D. Allen, 1980. Review of the factor electing the Quality and Ecceptability of health care. New York, SP Medicall and Scientific book,

Taufik. 1997. Bukan Sekedar Hadiah Besar. Majalah Info Bank, Nomor 205, Januari

Tjiptono Fandy. 1997. Strategi Pemasaran. Yogyakarta: Penerbit Andi Offset,

Tjiptono Fandy. 1995. Total Quality Management. Yogyakarta:
Warren William W. 1995. Relative Importance of Personal (Non Marketer) and Non-Personal (Market Dominated) Information Souces ini Adopting a Service Product, Kennet D. Bohn, Development ini Marketing Siensi, 1988, Edisi ke 11, hal. 345-349 Dikutip oleh Mona Sakaria, Mengelola Ketidakpuasan Nasabah dalam Konteks Pemasaran Layanan. Majalah Forum Manajemen Prasetya Mulya, Nomor 60,

Zeithaml Valarie A., A. Parasuraman, Leonard L. Berry, 1990 Delivering Quality Service Balancing Customer Perceptions and Expectations. New York: Free Press. 